\title{
Deformation modeling of polyvinylidenedifluoride(PVDF) symmetrical microfiltration hollow-fiber (HF) membrane
}

\author{
Shouichi Iio ${ }^{1}$, Akio Yonezu ${ }^{1 *}$, Hiroshi Yamamura ${ }^{2 *}, \mathrm{Xi} \mathrm{Chen}^{3,4^{*}}$ \\ 1. Department of Precision Mechanics, Chuo University, 1-13-27 Kasuga, Bunkyo, \\ Tokyo, 112-8551, Japan \\ 2. Department of Integrated Science and Engineering for Sustainable Society, Chuo \\ University, 1-13-27 Kasuga, Bunkyo, Tokyo, 112-8551, Japan \\ 3. Department of Earth and Environmental Engineering, Columbia University, $500 \mathrm{~W}$ \\ 120th Street, New York, NY 10027, USA \\ 4. International Center for Applied Mechanics, SV Lab, School of Aerospace, Xi'an \\ Jiaotong University, Xi'an 710049, China
}

\section{*Contact address}

\author{
$\underline{\text { Akio Yonezu }}$ \\ yonezu@mech.chuo-u.ac.jp \\ Tel: +81-3-3817-1829 / Fax: +81-3-3817-1820 \\ Hiroshi Yamamura \\ yamamura.10x@g.chuo-u.ac.jp \\ Tel: +81-3-3817-7257 / Fax: +81-3-3817-7257 \\ $\underline{\mathrm{Xi} \text { Chen }}$ \\ xichen@columbia.edu \\ Tel: +1-212-854-3787 / Fax: +1-212-854-7081
}




\begin{abstract}
The tensile deformation behavior of polyvinylidenedifluoride (PVDF) symmetrical microfiltration hollow-fiber (HF) membranes was studied. The membraneshad submicron pores with a three-dimensionalopen-cell structure. The surface and cross section of the porous membranes were observed by FESEM (field emission scanning electron microscope)to investigate the microstructure of the cell,namely, its size and ligament geometry. During uniaxial tensile tests, the membranes underwent elastic deformation and plastic deformation. Large deformation inducedpore growth along the tensile direction, resulting in anincrease in water permeability. In order to establish a mechanical model for tensile deformation, the finite element method (FEM) was employed. In this model, the Kelvin polyhedron (truncated octahedron structure) was used to mimica three-dimensionalopen-cell structure. Aone-unit cell based on this structure was created, and a periodical boundary condition was employed for the FEM computation. The FEM model could reproduce the overall elastoplastic deformationbehavior of the porous membrane andprovide useful insight into the fabrication of porous membranesand reliable operation of water purification.
\end{abstract}

Keywords: Symmetrical microfiltration hollow-fiber membranes;three-dimensional porous structure;tensile deformation; finite-element method; water permeability 


\section{Introduction}

Membrane filtration is a promising technology in the treatment of drinking and waste water, because it removes suspended solids without the addition of any chemicals[1]. Among the varioustypes of polymeric membranes (i.e.,flat sheet, hollow fiber and tubular type),hollow-fiber (HF) membranesare often used for water purification processes because they provide a large membrane area in a limited space[2, 3]. In practical operation, the accumulation offoulantson the membrane isa major obstacle to theefficient use of membrane processes.Such accumulation is routinely mitigated by physical cleaning[4-7], which includes air scrubbing, whichcauses the HF membranesto mechanically vibrate, consequentlyleading to detachment of accumulated contaminants from the membrane surface.Strong repetitive cleaningalso potentially leads to fatigue damage of the HF membrane; in practice, breakage of the HF membrane on the edge of the potting in membrane modulesis common [8].To improve the fracture properties of HF membrane, membraneswith high elongation and high strength have been developed by fabrication of prototypes; however, structure optimization of such membranes is still in an early stage.

Both macroscopic and microscopic dimensions of the membrane govern the mechanical strength of the membrane, and the inherent pore structure has inferior mechanical property compared with "solid" counterparts (matrix materials)[3, 9-13]. However, there is still a lack of knowledgeofthe relationship between three-dimensional structures of porous matrixesand their mechanical characteristics (i.e., macroscopic deformation and fracture strength of the entire fiber membrane). As a result, optimization of the physical properties of porous membranes is done by trial and error. 
Our previous study examined the mechanical deformation and inherent pore structureof polytetrafluoroethylene (PTFE)hollow-fiber membranes used for water purification[14]. Structural analysis using the finite element method (FEM)based ona simple pore structure model was carried out. Insight from this study may provide new guidelinesfor improvingthe physicaland mechanical properties of fiber membranes. However, our model consists of a very simple structure with only two dimensions;it needs to be extended tothree-dimensional space and structure to account more accurately for therelationshipbetween microscopic property and macroscopic deformation.

The present studyexaminedthe deformation behavior of apolyvinylidenedifluoride (PVDF)symmetrical microfiltration (HF) hollow-fiber membrane under uniaxial tensile loading, experimentally and numerically. We used the HF membrane,which has a symmetrical structure,fabricated by a thermally induced phase-inversion process. Tensile tests with various strain rates were carried out to observethe mechanicalpropertiesof the membrane (i.e., stress-strain curve), including yield stress and tensile strength. Furthermore, we investigatedhow the pore structure changed according tothe applied tensile strain.Water permeabilityas a function of the applied strain was also investigated. On the basis ofexperimental results, we propose a three-dimensional mechanical model with a porous structure and studied its behavior by using FEM. The predictive modelmaybe useful for designing structureswitha given polymer and porosity.The present studyshed light on the structural design of poresfor physical cleaning and onthe reliabilityofwater purification.

\section{Materials and experimental setup}


The materials used in this study werehollow-fiber (HF) membranes forpurification of drinkingwater (UNA-620A, microza ${ }^{\circledR}$,Asahi Kasei Chemicals Corporation, Tokyo, Japan). Theseare commercially available module components for water purification[15]. The matrix wascrystallinePVDF (polyvinylidenedifluoride).A thermally induced phase-inversion processwas usedto create a pore structure for the filtering process. The membrane cross section hada symmetrical microstructure. Figures 1(a)-(d) show the configuration and microstructureof the tested material. It resemblesa tube and transports water throughits wall. The inlet is the outer tube surface and the outlet is the inner tube surface.During use, a number of $\mathrm{HF}$ membranes assemble into a bundle and forma purification module.As shown in Fig.1(a), the outer diameter is $1.23 \mathrm{~mm}$ and the inner diameter is $0.67 \mathrm{~mm}$. The wall thickness is approximately $0.28 \mathrm{~mm}$. The outer surface (Fig. 1(b)) and cross section (Fig. 1(c)) of the membrane were observed by afield emission scanning electron microscope, FESEM (JSM-7001F,JEOL Ltd.). The microstructure had a random network and an open-cell structure.The overall porosity was estimated to be $65 \%$ on the basis of density measurements. In such measurements, the volume of the HFmembrane was calculated according to the inner and outer diameters, as wellas the length of the membrane.The density of intrinsic PVDF (matrix material) of $1.78 \mathrm{~g} / \mathrm{cm}^{3}$ was used.

Figure 1(d) shows a magnifiedcross section in Fig.1(c). Theopen-cell structure consisted of a PVDF matrix ligament. The magnified view shows that the geometry of the PVDF ligament (strut) was not straight (i.e., non-uniform). We assumed that the PVDF ligament wasa cylindrical shape with constriction (i.e., hyperbolic cylinder shape). In other words, the diameter of the ligament was not constant and was presumablya hyperbolic shape with maximum and minimum diameters. The ratio 
between the maximum and minimum diameterswas obtained from FESEM observations. Figures 2(a) and (b) show the distributions of pore size and diameter ratio,respectively ${ }^{*}$. The size of pores in Fig. 2(a), which are assumed to be spherical, indicates that the average diameter was $160 \mathrm{~nm}$. In Fig.2(b), the average ratio of ligament diameter was 0.75. This microstructure was observed uniformly through the thickness of the membrane.

Uniaxial tensile tests were performed by usinga ball-screw-typeuniversal testing machine (AG-1, Shimadzu Corp.).The HF membrane waswound aroundthe testing fixture so that it applied uniform tensile stress to the membrane. The clamp distance corresponded tothe gauge length of about $174 \mathrm{~mm}$. The tests were conducted under displacementcontrol at room temperatureat strain rates of $4.8 \times 10^{-4}, 4.8 \times 10^{-3}$, and 1.4 $\times 10^{-2} 1 / \mathrm{s}$. For each test, average data ofat least three measurements ${ }^{\dagger}$ were obtained.

\section{Experimental results}

\subsection{Tensile-deformation behavior}

Figure 3 shows the nominal stress-strain curve foreach test atdifferent strain rates. Thenominal stress increasedlinearlywiththe increase in tensile strain and reachedaflexion point. The stress value thenincreased gradually after the flexion point. Finally, it reachedthe final fracture point(indicated by $x^{*}$ in this figure). The fracturealways occurrednear theboundary of the clamped area ofthe fixture because

\footnotetext{
* For this measurement, we selected various areas (whose total is larger than $100 \mu \mathrm{m}^{2}$ ). This is much larger than one pore size (about $0.02 \mu \mathrm{m}^{2}$ ). Thus, our measurement provides the average value for entire material.

${ }^{\dagger}$ We totally used 20 specimens in this study. These are in the same production lot. For FESEM observations, about five specimens were used.The remaining 15 specimens were used for the tensile tests.

${ }^{\ddagger}$ Just before complete fracture, the stress drastically went down to zero. However, this decreasing curve is not indicated in the figure, since we do not discuss the fracture point.
} 
ofstress concentration. This means that the stress applied wasnot uniform. To address this problem, a preliminary testwas conducted to determinehow the HF membranelocallydeformedunder tensile loading. The outersurface of the membrane was marked with paint at $15 \mathrm{~mm}$ intervals along the longitudinal direction. During tensile loading, mark distancewas measured by using a video camera todeducethelongitudinal strain distribution. We found that the tensile strain at each sectionhad uniform distribution up to the point just before final fracture. When itreachedthe final fracture point, the local area wherethe HFmembrane was wound on the fixture startednecking locally, resulting in membrane fracture. This observation indicates that the testing method could apply uniform tensile stress to the membrane fiber up to just before the final fracture.

As shown in Fig.3, the stress-strain curves dependedslightly onthe strain rate

$\varepsilon$,graduallyincreasingafter the flexion point. Such trend isoften observedin solid polymer materials[16, 17]. However, the effect of strain rate in this case may be minor. In contrast, the fracture strain wasrelativelyscatteredand thus might not be dependent on $\varepsilon$, because it depended primarilyon theclamped conditionand on stress concentration.

We then investigated how the HF membrane elastically and plastically deformed.In this study,loading and unloading testswerecarried out as shown in Fig.4. At a predetermined tensile load, the loading was stopped and reduced to zero ${ }^{\S}$. Several tests with varioussuspendedloads were conducted. In all tests, the strain rate was set at 4.8 $\times 10^{-3} 1 /$ s. Representative dataare plotted in Fig.4. The chosen suspendedloads were (A)

\footnotetext{
${ }^{\S}$ After the loading was reduced to zero, the specimen was unfixed from the jig. In particular, the bottom of the membrane specimen was unclamped from the jig such that the specimen matched thecompletely unloaded condition(no-loading condition). As described later, this test measured the strain in a noncontact manner using a video camera.
} 
$\left(\sigma_{\mathrm{n}}=3.53 \mathrm{MPa}, \varepsilon_{\mathrm{n}}=0.038\right),(\mathrm{B})\left(\sigma_{\mathrm{n}}=4.75 \mathrm{MPa}, \varepsilon_{\mathrm{n}}=0.43\right)$, and $(\mathrm{C}) \quad\left(\sigma_{\mathrm{n}}=5.29 \mathrm{MPa}\right.$, $\varepsilon_{\mathrm{n}}=0.72$ )as shown in Fig.4.

As shownin Fig.4, the unloading curvefor test (A) matchesthe loading curve, indicating that the specimen deformed elastically. However, in the tests (B) and (C), loading and unloading histories are not identical, and the strain remains after full unloading. We presumedthat beyond the flexion point, the specimen underwent plastic deformation. After complete unloading, we carefully observed the changes in total strain. The results plotted in Fig.5(a)show the strain history after complete unloading (i.e., the specimen was left in a no-loading statefor up to 72 hours ( 2 days)). In both tests, the strain decreasedwith the testing time and then reacheda constant value. This is time-dependent behaviorsimilar toviscoelastic recovery. However, the strain did not recover completely. The remaining strain values, i.e., the remaining plastic strain after complete recovery(plottedin Fig.5(b)) indicate that the plastic strain depended on the applied tensile strain. This means that the specimensfrom tests(B) and (C) underwentplastic deformation, with plastic strain remaining. Therefore, the flexion point in the stress-strain curve (in Fig.4) is the yield point. Thus, we canconclude that the specimen first deformedelastically and then developed a flexion point due to macroscopic plastic deformation. Such unique behavior might be due to the inherent pore structure and the properties of the PVDF matrix.

\subsection{Changesin porous structure}

We furtherinvestigated how the pore structure changed according to the applied tensile strain. Several tensile tests were carried out atvarious suspended strains, as shown in Fig.6(a). Those tests are designated as tests (1), (2), (3), (4), (5), and (6) in 
Fig.6(a). After full unloading, we observed the porous structure of the surface by using FESEM (micrographs are shown in Fig.6(b)). Test (1) involveda no-loading specimen (i.e., an as-received specimen); the tensile direction follows thelongitudinal direction of the graph. As shown in test (2), the range of elastic deformationindicates no changes in porous structure, as compared with that in test (1).However, test (4)produced a slightly different structure beyond the yield point, suggesting that the pore grew slightly. After further application of tensile strain, the porous structure significantly changed. We found that the pore grewalong the longitudinal direction of uniaxial tension. The surrounding matrix (PVDF ligament) stretched because of plastic deformation.Therefore, the applied strain ledto the thinning ofthe PVDF ligament. Thisisthe mechanismof macroscopic plastic deformation of the HF membrane.

Figure 7 shows the change in pore structure with respect to the applied tensile strain. We carefully measuredthe pore area in each test(Figs.6(b), test (1)-(6)) and plotted the pore diameter (we assumed that the poreswerespherical) ${ }^{* *}$.Designations (1)-(6) for "Test code number" are the same as those in Figs. 6. After the yield stress (from test (3)), the pore size increased.This increase is due to plastic stretching of the matrix fiber. Notably, these observations were obtained after full unloading using FESEM. Therefore, our observationson pore structure may differ from those undertensile loading,i.e., the pore size (in Fig.7) was slightly smallerbecause of elastic recovery due tounloading.

Water permeability tests were carried outon the deformed specimens to investigate how tensile deformation affects water purification. The present HF membrane with 100 $\mathrm{mm}$ length was prepared. One membranewasimmersed in pure water, and then pure

\footnotetext{
*** This measurementprocedure is the same with Figs.2.
} 
water was pulled from the inner diameter of the membrane under controlled flow velocity. Water wasthusfiltered through the thickness of membrane. One end of the membrane was filled with resin bond and the other was left open for pulling pure water for the water permeability test. In other words, the outer surface of the membranewas theinlet and the inner surface was the outlet. Wecontinuouslymeasuredthe pressurevariation offlowingwater under constant flow velocity, and then we calculatedthe coefficient of water permeability. Figure 8 shows the changes in coefficient of water permeability withapplied tensile strain. Designations (1)-(6) for "Test code number" are the same as those in Fig.7. The water permeability significantly increased when plastic deformation was large. This increase occurredbecause of the increase in pore size due to the tensile loading, as shown in Fig.7. This suggests that plastic deformation of the HF membrane is critical to water purification.

The results reveal that the pore structure was changed by plastic deformation of the PVDF ligament.This mechanism was a key factor in the macroscopic deformation and water purification functionality of the hollow-fiber membranes.To establish the computational approachfor simulating themacroscopic deformation of the membrane, we then employed FEM incorporating the pore structure.

\section{Mechanical model}

Acomputationalapproachwas established to predict the tensile deformation behavior of the present PVDFhollow-fiber membranes. As discussed above, the macroscopic deformation depends on the elastoplastic properties of PVDFmatrix and on the inherent porous structure. Thus, athree dimensional (3D) FEM model including the pore structure was constructed (Section 4.1).We then exploredthe agreement between 
the computed and experimental stress-strain curves.In this process, both elastic and elastoplastic analyses were conductedtoinvestigate whether the computational and experimental stress-strain curves agree (Section 4.2).

\subsection{Finite element simulation}

Figures 9(a)-(d)presenta model of the porous structure for the FEM computation. The SEM image of the open-cell structure is shown in Fig.9(a) (see Fig.1(d)).To model the three-dimensional porous structure, a Kelvin polyhedron type was used in Fig.9(b).A truncated octahedron structure was chosen to enable space filling of an open cell[18, 19]. Figure 9(c) shows acollective model using the Kelvin polyhedron, which wasschematically drawn by using three-dimensional CAD software (Inventor, Autodesk Inc.). As shown in Figs. 1 and2, a porosity of $65 \%$ and an average pore diameter of 160 nm were used to createthe Kelvin polyhedron structure. As shown in Fig.9(d), we extracted one unit cell from the collective structure andapplied a periodic boundary condition for theFEM computation. We noted that the matrix ligament surrounding the pore was not straight and uniform, as shown in Fig.2(b). As a result, the ligament (strut) of this model was not uniform, as depicted in themagnified image in Fig.9(d). The ratio of maximum to minimum diameter determined from the SEM observations is 0.75 (Fig.2(b)). On the basis of information obtained through observation, we created a non-uniform strut model with a Kelvin structure as shown in Fig.9(d).

Finite element method (FEM) is carried out using Marc Mentat 2013.1.0 (MSC Software Corporation). Atetrahedral element (primary element type ${ }^{\dagger \dagger}$; Fig. 9(d)) was used. Fine meshes were created around the regions of stress/strain concentration, and a

\footnotetext{
${ }^{\dagger}$ We also usedtetrahedral element with secondary element type to avoid volumetric locking. This computation result agrees with our model with a primary element type.
} 
mesh convergencestudy was carried out. The numbers of nodes and elementswere72,803 and 371,090, respectively.The computed FEM model is shown in Fig.10. For this model, the left end of the unit was fixed, and the right end wasextendedby using a uniaxial tensile load. In addition, a periodic boundary condition wasapplied to the model (i.e.,the side surface of the $\mathrm{x}-\mathrm{y}$ plane for the zdirection, and that of the $\mathrm{x}-\mathrm{z}$ plane for the ydirection). At the right end, the longitudinal displacement and reaction force werecomputed to obtain the nominal stress-strain curve, which was thencompared with the experimental stress-strain curve.

Elastic and plastic deformation regions were observed(Figs.3 and 4). Thus,we conducted elastic and elastoplastic FEM analyses, respectively. For the constitutive equation, elastic deformation obeys Hook's law, and plastic deformation is non-liner equation as described in Eg.(1) (see later). The yield criterion is assumed to be Mises criterion. We employed the elastoplastic properties of the PVDF matrix obtained from the previous study [20], in whichthe uniaxial tensile stress and strain curve of bulk PVDF wasmeasured. According to the study [20], the crystalline phase of PVDF wasan $\alpha$ phase, which is the same as our specimen (as measured byFourier transform infrared spectroscopy). The stress-strain curve during plastic deformation was approximated from the phenomenological constitutive law [14, 17]:

$$
\sigma=\sigma_{Y}+K \varepsilon_{p}{ }^{n}
$$

where $\sigma_{\mathrm{Y}}$ is yield stress, $K$ is the work hardening coefficient, $n$ is the work hardening exponent, and $\varepsilon_{\mathrm{p}}$ is plastic strain. These material constantswereextractedfor the elastoplastic property, as shown in Table 1. Here, the yield stress was assumed to be the 
offset stress at a strain of $2 \%$ (i.e.,the offsetyield stress, $\sigma_{2} \%$. Although the polymer material generally showeda strain rate effect duringboth elastic and plastic deformation, the result shows little effect on the stress-strain curve in Fig.3. Thus, this study did not consider the strain rate effect on the elastoplastic property.

\subsection{Deformation behavior}

Figure 11 shows stress-strain curvesobtained through both experiment (same asin Fig.3) and computations. Resultsofelastic analysisare indicated by an open circle $(\bigcirc)$ and those of the elastoplastic analysis are represented by a triangle $(\triangle)$. Thereis good agreement between the elastoplastic deformation observedby experiment and that derived from computations. The inserted figure shows a contour mapof equivalent stress $\left(\sigma_{\mathrm{eq}}\right)$ distribution for the specimen that deformed plastically. It reveals thatthe PVDF ligament (strut) stretched plastically, resulting in pore growth.Pore size was also investigated by FEM. As an example case, the pore diameterwas $0.2 \mu \mathrm{m}$ when the tensile strain was 0.43 , which is in good agreement with the experimental result $(0.28$ $\mu \mathrm{m})$. This agreement suggests that our computation may also be useful for predicting microscopic properties such as pore size.

The results for Young's modulus $(E)$ and $\sigma_{Y}$ (proof stress, $\sigma_{2 \%}$ ) are presented in Table 2. Although these material constants are dependent on $\varepsilon$ (see Fig.3), the computational curvereasonablyagrees with that from the experiments. Thus, our model is useful for simulating tensile deformation behavior.

\footnotetext{
${ }^{*}$ The offset yield stress (proof stress) is usually set to $\sigma_{0.2}$ at $0.2 \%$ strain, but the polymer material sometimes undergoesnonlinear elastic deformation. Thus, several studies use the offset stress at $2 \%\left(\sigma_{2 \%}\right)$ (seethe study by Rae et al.[15]).
} 


\section{Conclusion}

This study proposed a computational framework to simulate the tensile deformation behavior of PVDF symmetrical microfiltration hollow-fiber membranes. The HF membraneshad submicron pores with athree-dimensional open-cell structure. We first observed the microstructure surface and cross section of the membranes by FESEM to investigate their pore structure (i.e., cell size and geometry of the ligament/strut). Their porosity was found to be $65 \%$. Uniaxial tensile tests revealed that the HFmembranes underwent elastic deformation and plastic deformation. Large tensiledeformation inducedPVDF ligament stretching and pore growth, resulting in increased water permeability. This result suggests that the water filtration capacity decreased.

FEM was employedto establish a mechanical model for tensile deformation. In this model, a Kelvin polyhedron (truncated octahedron structure) was used to mimic a three-dimensional open-cell structure. Aone-unit cell based on this structure was created, 


\section{Acknowledgments}

The authors are grateful to Mr. Masumi Anazwa at Chuo University for his important contributions to the experiments. This work was supported by the "Nanotechnology Platform" (project no.12024046) of the Ministry of Education, Culture, Sports, Science and Technology, Japan. The work of A.Y. is supported by JSPS KAKENHI (grant no. 26420025) from the Japan Society for the Promotion of Science, by a research grant from JGC-S Scholarship Foundation (no.1425), and by The Sumitomo Foundation (Environmental Research Projects, no.143127). The work of X.C. is supported by the National Natural Science Foundation of China (11302163, 11172231 and 11372241), ARPA-E (DE-AR0000396), and AFOSR (FA9550-12-1-0159).

\section{References}

[1] Shannon MA, Bohn PW, Elimelech M et al. Science and technology for water purification in the coming decades. Nature 2008; 452:301-310.

[2] Mulder J. Basic Principles of Membrane Technology. Kluwer Academic Publishers; 1996.

[3] Tang Y, Li N, Liu A et al. Effect of spinning conditions on the structure and performance of hydrophobic PVDF hollow fiber membranes for membrane distillation. Desalination 2012; 287:326-339. [4] L.S. Tam, T.W. Tang, G.N. Lau et al. A pilot study for wastewater reclamation and reuse with MBR/RO and MF/RO systems. Desalination 2007; 202:106-113. 
[5] Xiafu Shi, Galit Tal, Nicholas P. Hankins, Gitis V. Fouling and cleaning of ultrafiltration membranes: A review. Journal of Water Process Engineering 2014; 1:121-138.

[6] Heng Liang, Weijia Gong, Jie Chen, Li G. Cleaning of fouled ultrafiltration (UF) membrane by algae during reservoir water treatment. Desalination 2008; 220:267-272.

[7] Suck-Ki Kang, Kwang-Ho Choo, Desalination. Use of submerged microfiltration membranes for glass industry wastewater reclamation: pilot-scale testing and membrane cleaning. Desalination 2006; 189:170-180.

[8] Matsumoto Y, Miwa T, Nakao S, Kimura S. Improvement of membrane permeation performance by ultrasonic microfiltration. Journal of chemical engineering of Japan 1996; 29:561-567.

[9] Amy E. Childress, Pierre Le-Clech, Joanne L. Daugherty et al. Mechanical analysis of hollow fiber membrane integrity in water reuse applications. Desalination 2005; 180:5-14.

[10] Sukitpaneenit P, Chung T-S. Molecular elucidation of morphology and mechanical properties of PVDF hollow fiber membranes from aspects of phase inversion, crystallization and rheology. Journal of Membrane Science 2009; 340:192-205.

[11] Jason A. Morehouse, Douglas R. Lloyd, Benny D. Freeman et al. Modeling the stretching of microporous membranes. Journal of Membrane Science 2006; 283:430-439.

[12] Nana Li, Changfa Xiao, Shulin An, Hu X. Preparation and properties of PVDF/PVA hollow fiber membranes. Desalination 2010; 250:530-537.

[13] Hanks PL, Kaczorowski KJ, Becker EB, Lloyd DR. Modeling of uni-axial stretching of track-etch membranes Journal of Membrane Science 2007; 305:196-202.

[14] Yonezu A, Iio S, Itonaga T et al. Tensile deformation of polytetrafluoroethylene (PTFE) hollow fiber membrane used for water purification. Water Science and Technology 2014; 70:1244-1250.

[15] https://www.asahi-kasei.co.jp/membrane/microza/en/customer_water.html. In.

[16] Rae PJ, Brown EN. The properties of poly(tetrafluoroethylene) (PTFE) in tension. Polymer 2005; $46: 8128-8140$.

[17] Nunes LCS, Dias FWR, Mattos HSdC. Mechanical behavior of polytetrafluoroethylene in tensile loading under different strain rates. Polymer Testing 2011; 30:791-796.

[18] Jang WY, Kraynik AM, Kyriakides S. On the microstructure of open-cell foams and its effect on elastic properties. International Journal of Solid and Structures 2008; 45:1845-1875.

[19] Sullivan RM, Ghosn LJ, Lerch BA. A general tetrakaidecahedron model for open-celled foams. International Journal of Solid and Structures 2008; 45:1754-1765.

[20] Kuila A, Chatterjee DP, Layek RK, Nandi AK. Coupled Atom Transfer Radical Coupling and Atom Transfer Radical Polymerization Approach for Controlled Grafting from Poly(vinylidene fluoride) Backbone. Journal of Polymer Science, Part A: Polymer Chemistry 2014:995-1008. 


\section{List of Tables and Figures}

Fig.1 Configuration and microstructure of the hollow-fiber membrane; (a)macroscopic view of cross section, (b) outer surface, (c) cross section, and (d) magnified view of (c). Fig.2 Distribution of pore size (a) and diameter ratio of ligament (b) of the hollow-fiber membrane.

Fig.3 Experimental nominal stress-strain curves at various strain rates.

Fig.4 Nominal stress-strain curves of repeated loading-unloading tests.

Fig.5 Changes in total strain as a function of testingtime after full unloading (a), andplastic strain with respect to the applied strain (b).

Fig.6 Nominal stress-strain curve (a) and micrographsfrom several tensile tests at various suspended strains (b).

Fig.7 Changes in pore size with respect to the applied strain. The designations of (1)-(6) are the same with the legend of Fig.6(a).

Fig.8 Changes in coefficient of water permeability with the applied strain.The designations of (1)-(6) are the same with the legend of Fig.6(a).

Fig.9 FEM model of the 3D open-cell structure and SEM image of the porous structure with an open cell ina hollow-fiber membrane (a),Kelvin cell structure (b), cluster of Kelvin cell foams (c), and one unit cell extracted from the cluster modelfrom panel (c) (d).

Fig.10 FEM model of one unit cell inFig.9(d) under the boundary condition.

Fig.11 Nominal stress-strain curvesfrom experiment and FEM(circle: elastic analysis, triangle: elastoplastic analysis). Experimental data were obtained from Figure 3.

Table 1 Mechanical properties of the PVDF solid matrix.

Table 2 Mechanical properties (Young's modulus and yield stress)obtainedfrom the experimental stress-strainand FEM computationalcurves(see Fig.11). 


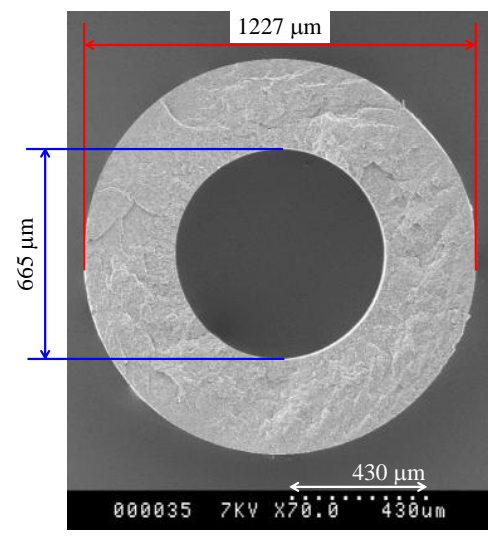

(a)(b)

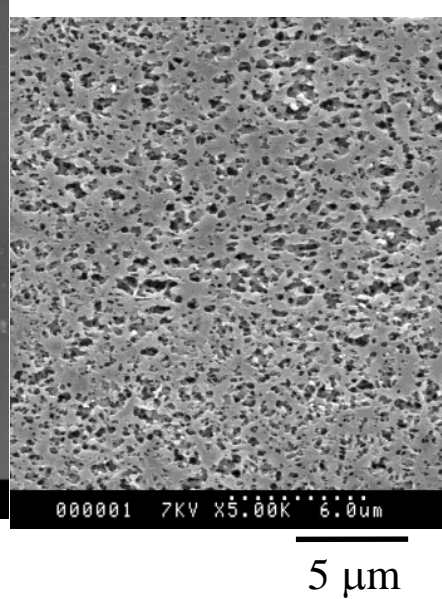

(c)

c)
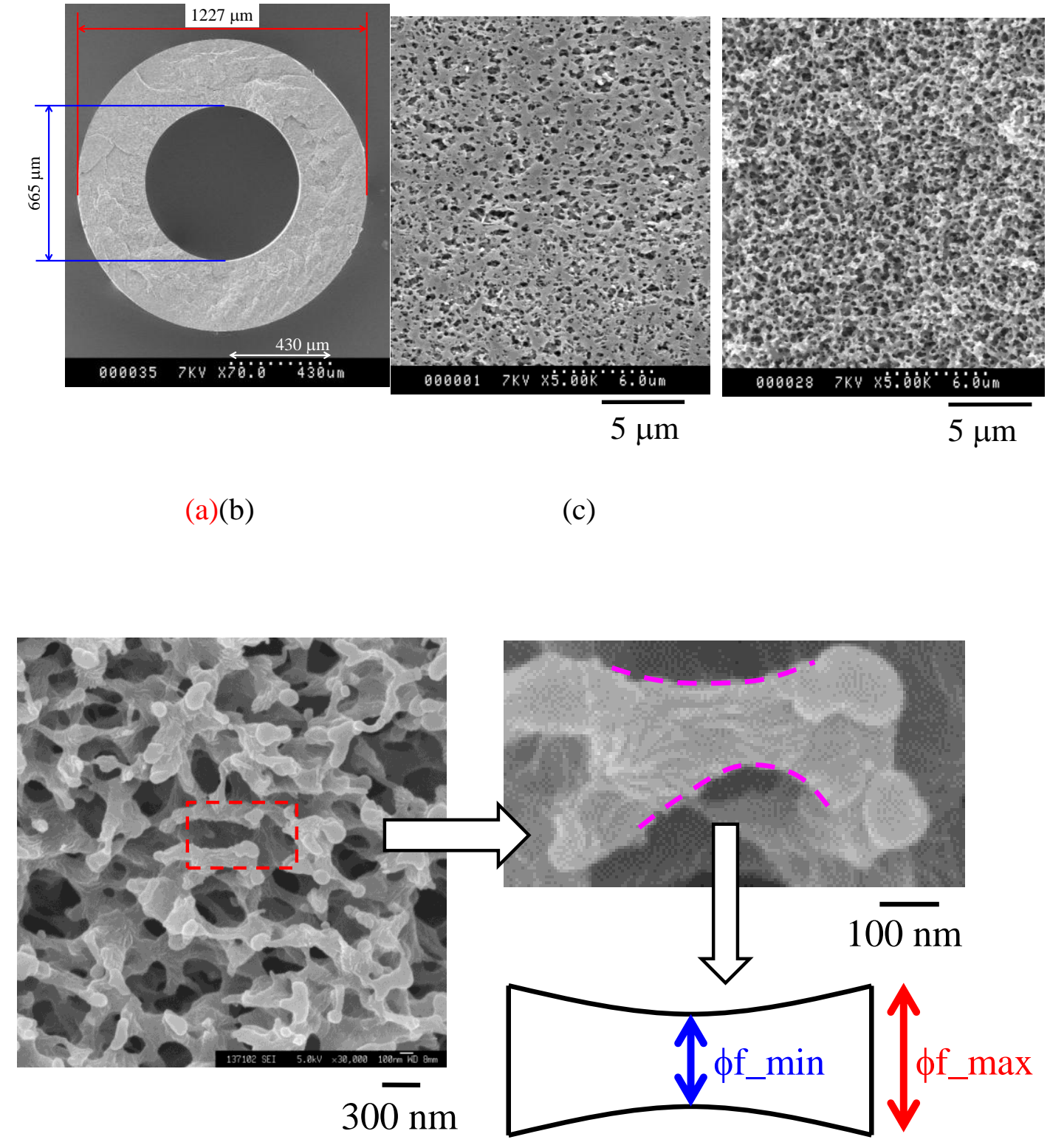

(d)

Fig. 1 Configuration and microstructure of the hollow-fiber membrane; (a) macroscopic view of cross section, (b) outer surface, (c) cross section, and (d) magnified view of (c). 


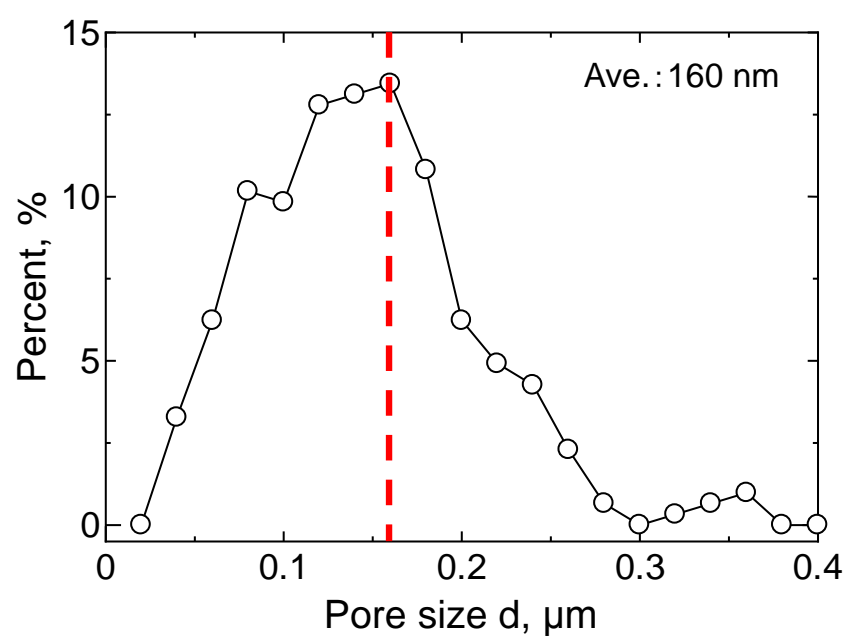

(a)

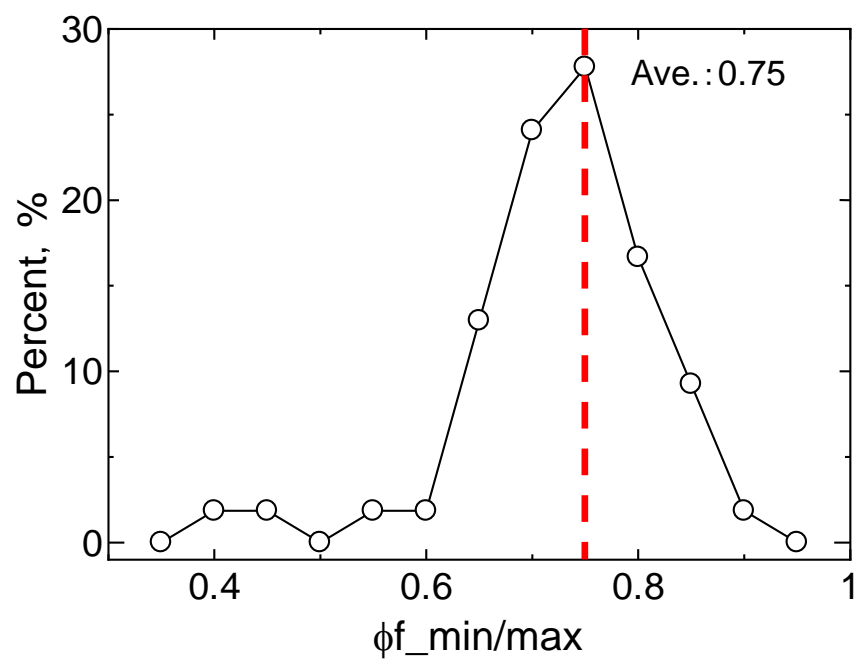

(b)

Fig. 2 Distribution of pore size (a) and diameter ratio of ligament (b) of the hollow-fiber membrane. 


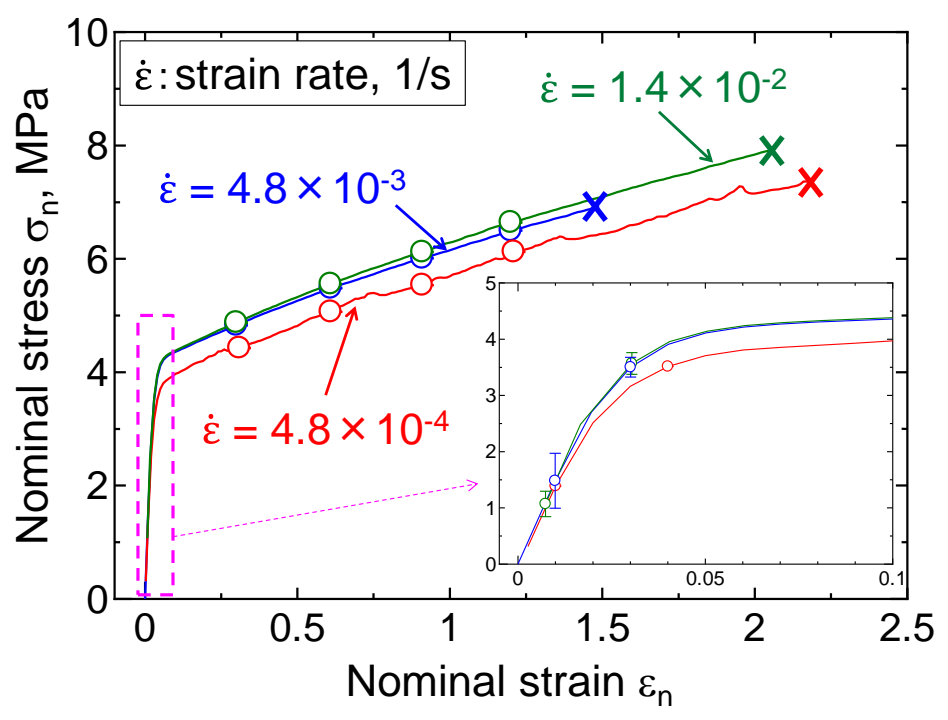

Fig. 3 Experimental nominal stress-strain curves at various strain rates.

\begin{tabular}{|c|c|c|c|}
\hline & $O(A)$ & $\square(B)$ & $\diamond(C)$ \\
\hline$\sigma_{n}, \mathrm{MPa}$ & 3.53 & 4.75 & 5.29 \\
\hline$\varepsilon_{\mathrm{n}}$ & 0.038 & 0.43 & 0.72 \\
\hline
\end{tabular}

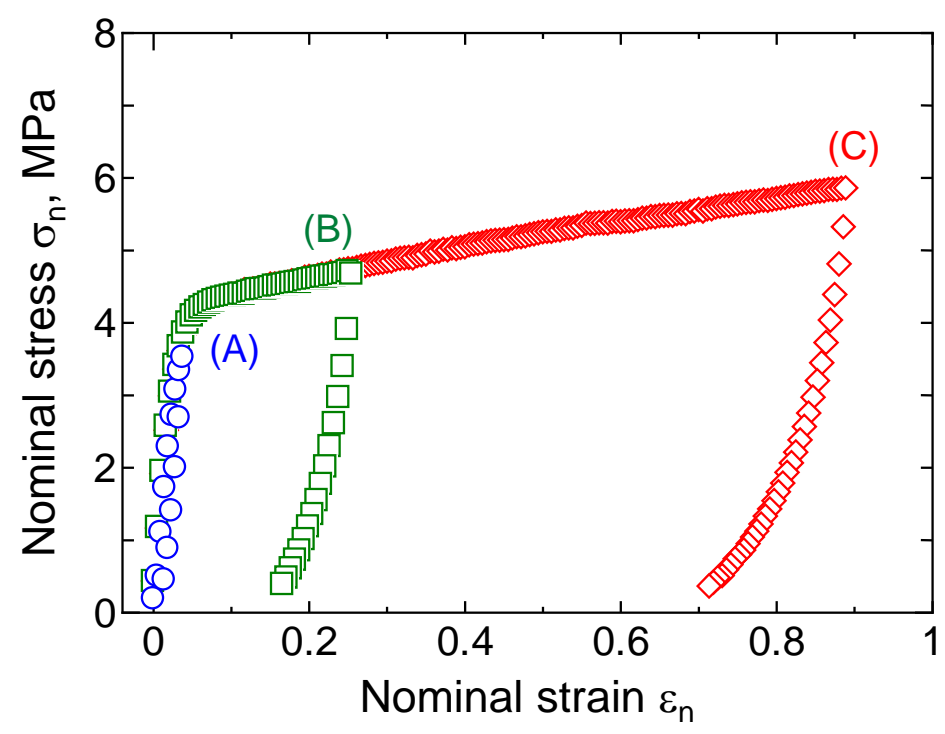

Fig. 4 Nominal stress-strain curves of repeated loading-unloading tests. 


\begin{tabular}{|c|c|c|c|}
\hline & $O(A)$ & $\square(B)$ & $\diamond(C)$ \\
\hline$\sigma_{n}, \mathrm{MPa}$ & 3.53 & 4.75 & 5.29 \\
\hline$\varepsilon_{n}$ & 0.038 & 0.43 & 0.72 \\
\hline
\end{tabular}

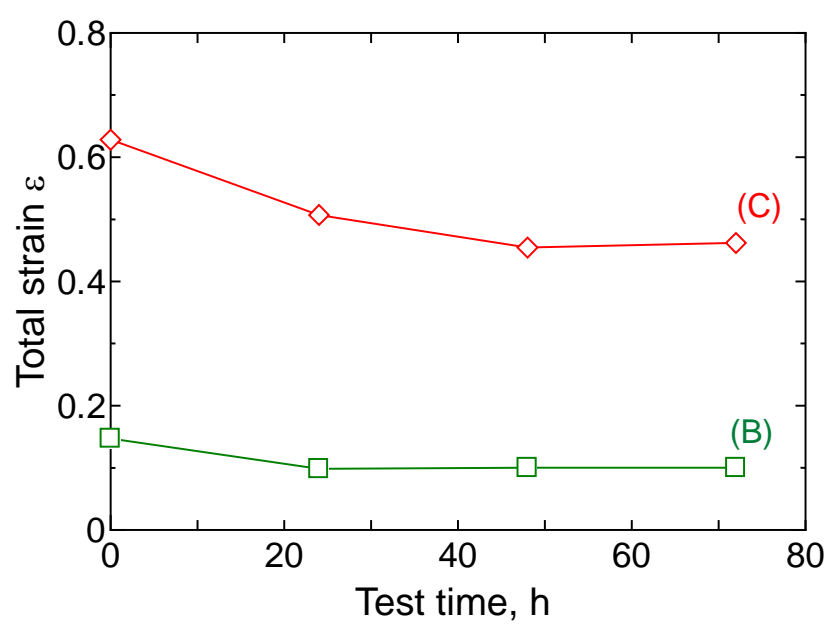

(a)

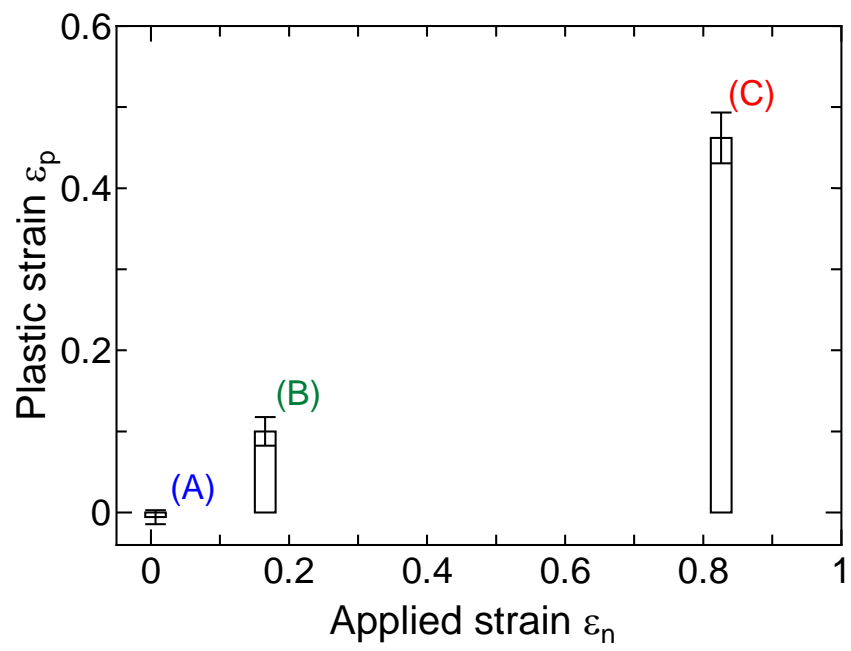

(b)

Fig. 5 Changes in total strain as a function of testingtime after full unloading (a), andplastic strain with respect to the applied strain (b). 


\begin{tabular}{|c|c|c|c|c|c|c|}
\hline Test & $(1)$ & $(2)$ & $(3)$ & $(4)$ & $(5)$ & $(6)$ \\
\hline$\sigma_{n}, \mathrm{MPa}$ & 0 & 3.53 & 4.71 & 5.29 & 6.46 & 6.94 \\
\hline$\varepsilon_{\mathrm{n}}$ & 0 & 0.04 & 0.43 & 0.72 & 1.49 & 1.70 \\
\hline
\end{tabular}

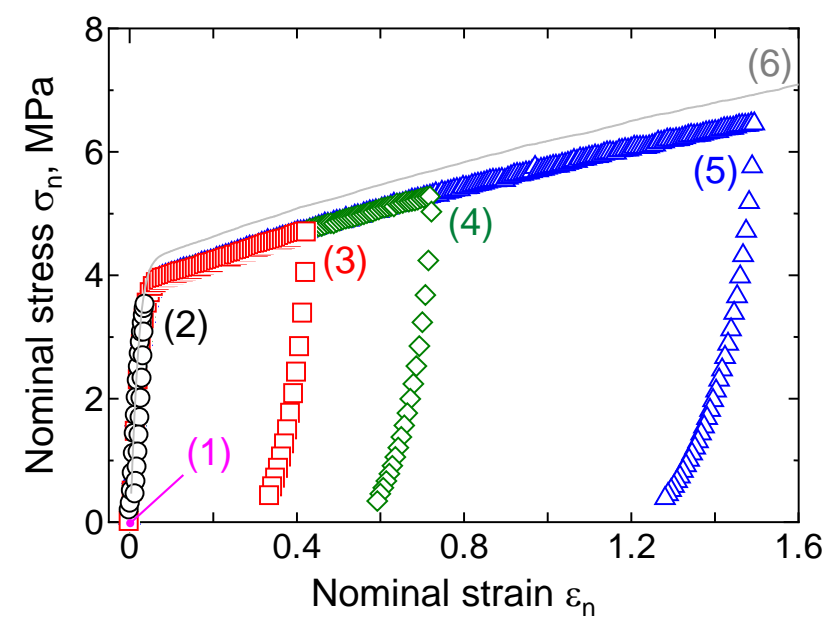

(a)
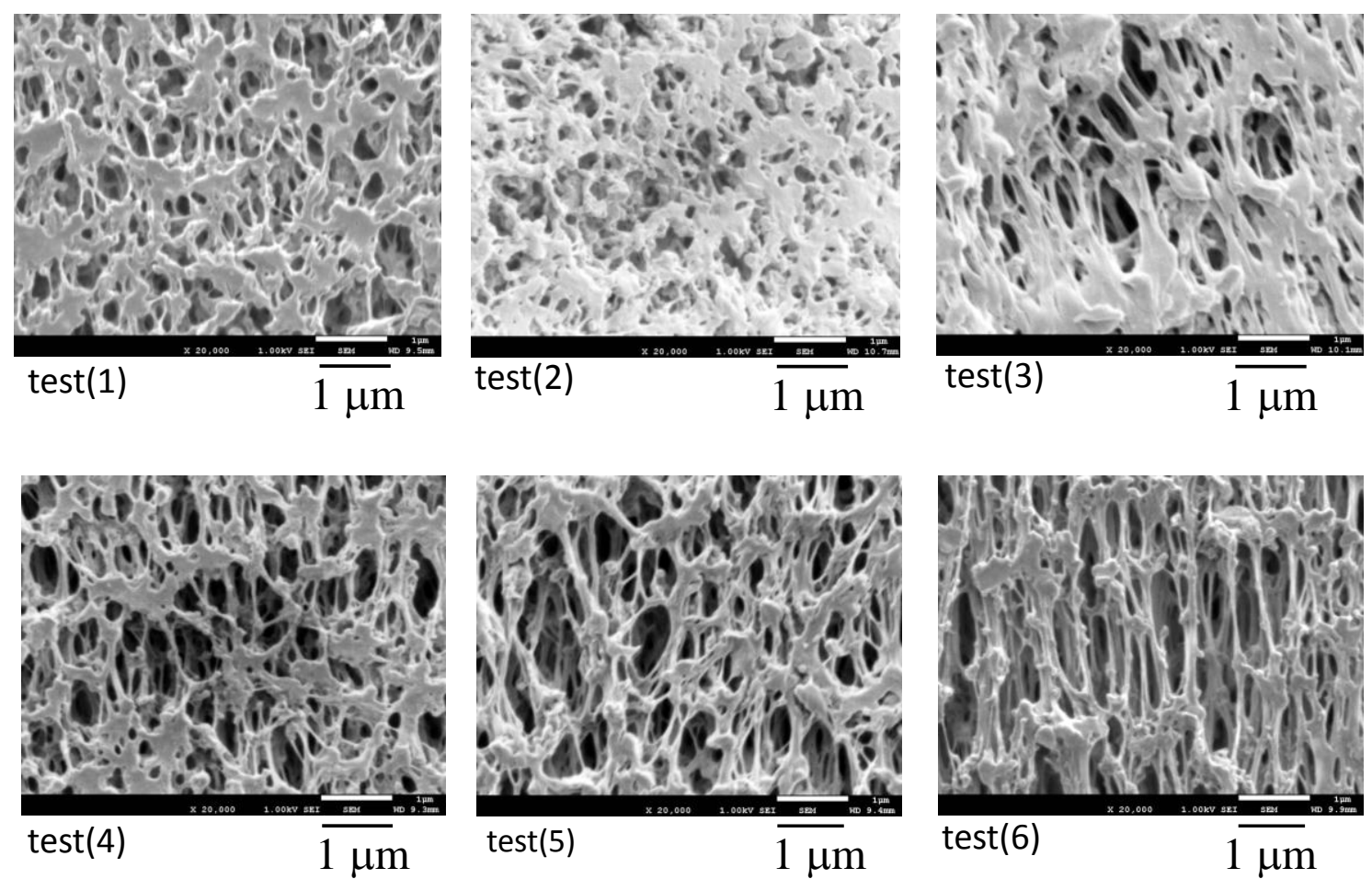

(b)

Fig. 6 Nominal stress-strain curve (a) and micrographs from several tensile tests at various suspended strains(b). 


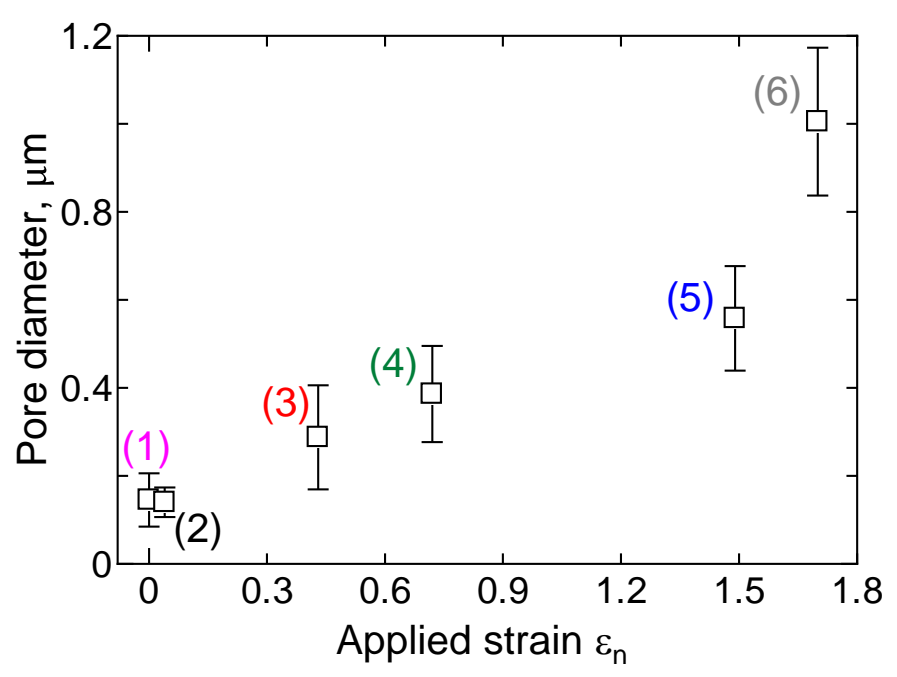

Fig. 7 Changes in pore size with respect to the applied strain. The designations of (1)-(6) are the same with the legend of Fig.6(a).

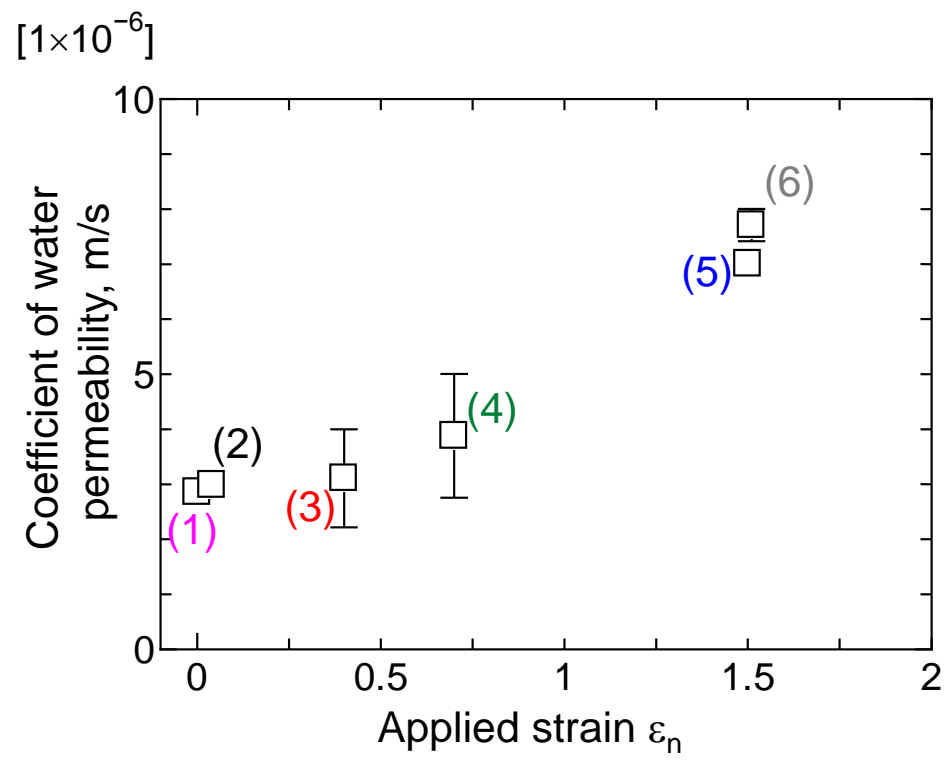

Fig. 8 Changes in coefficient of water permeability with the applied strain. The designations of (1)-(6) are the same with the legend of Fig.6(a). 


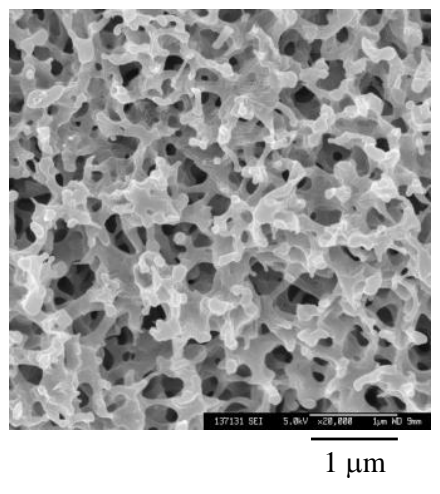

(a)

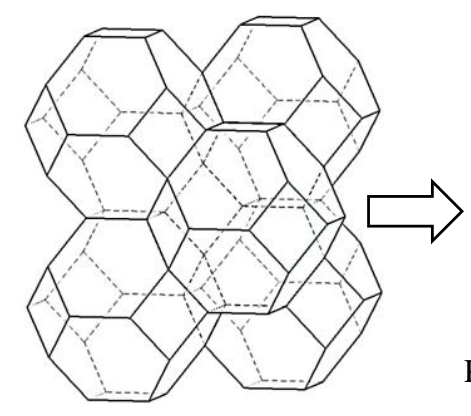

(b)

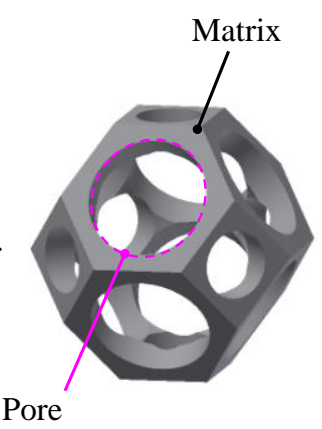

Pore

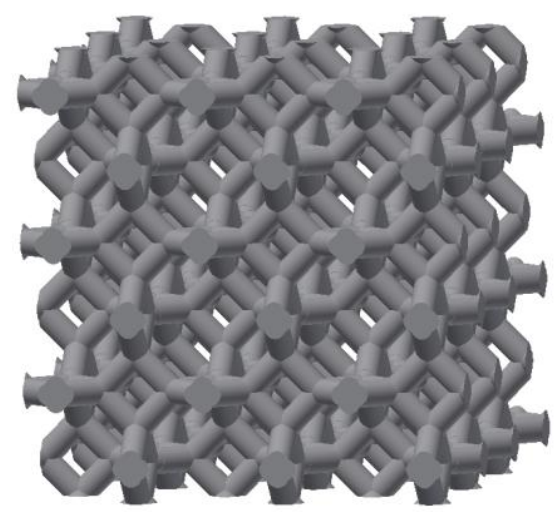

(c)
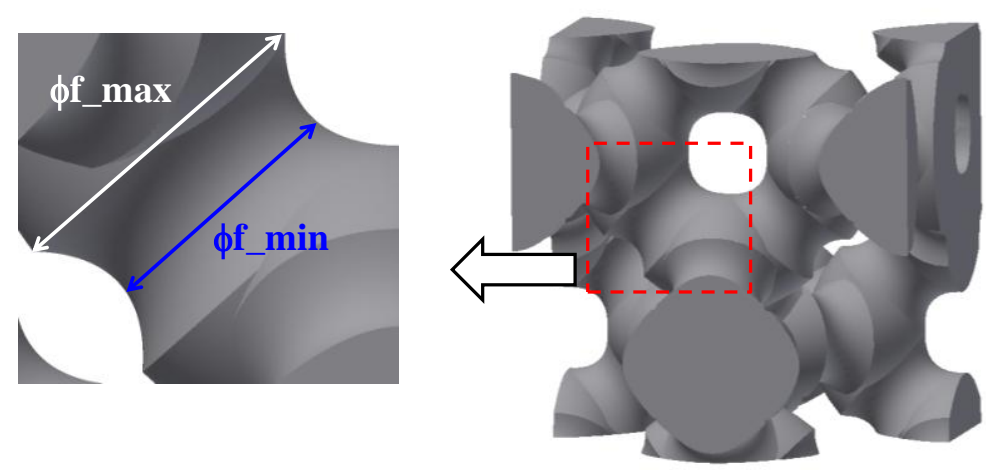

(d)

Fig. 9 FEM model of the 3D open-cell structure and SEM image of the porous structure with an open cell in a hollow-fiber membrane (a),Kelvin cell structure (b), cluster of Kelvin cell foams (c),and one unit cell extracted from the cluster modelfrom panel (c) (d). 


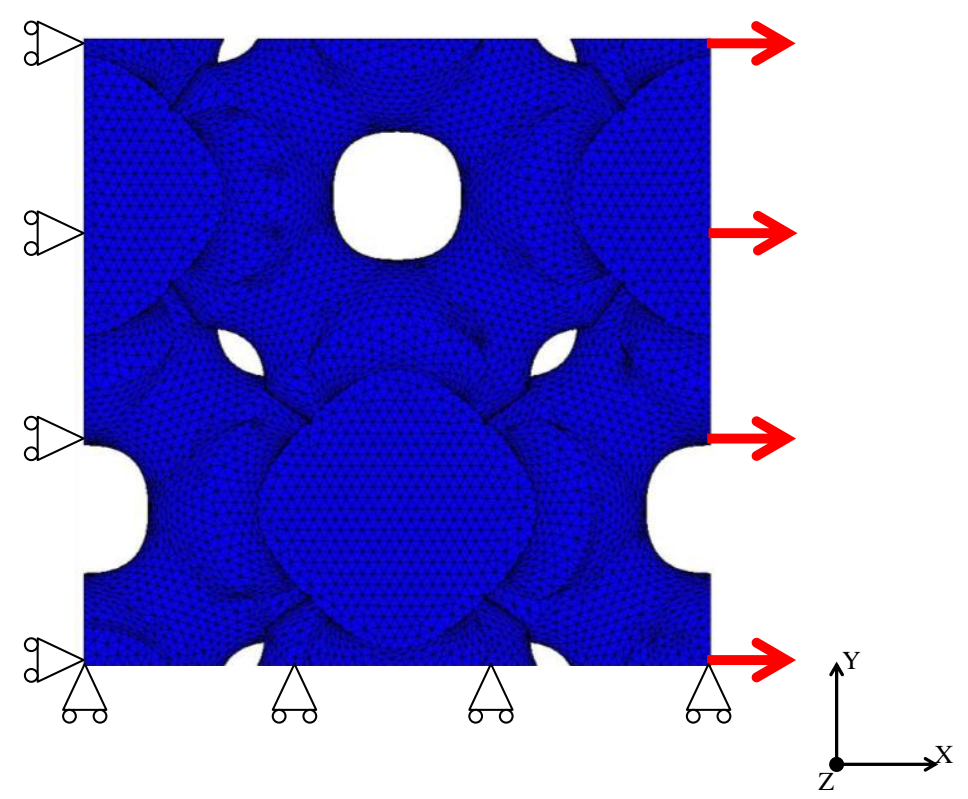

Fig. 10 FEM model of one unit cell in Fig.9(d) under the boundary condition.

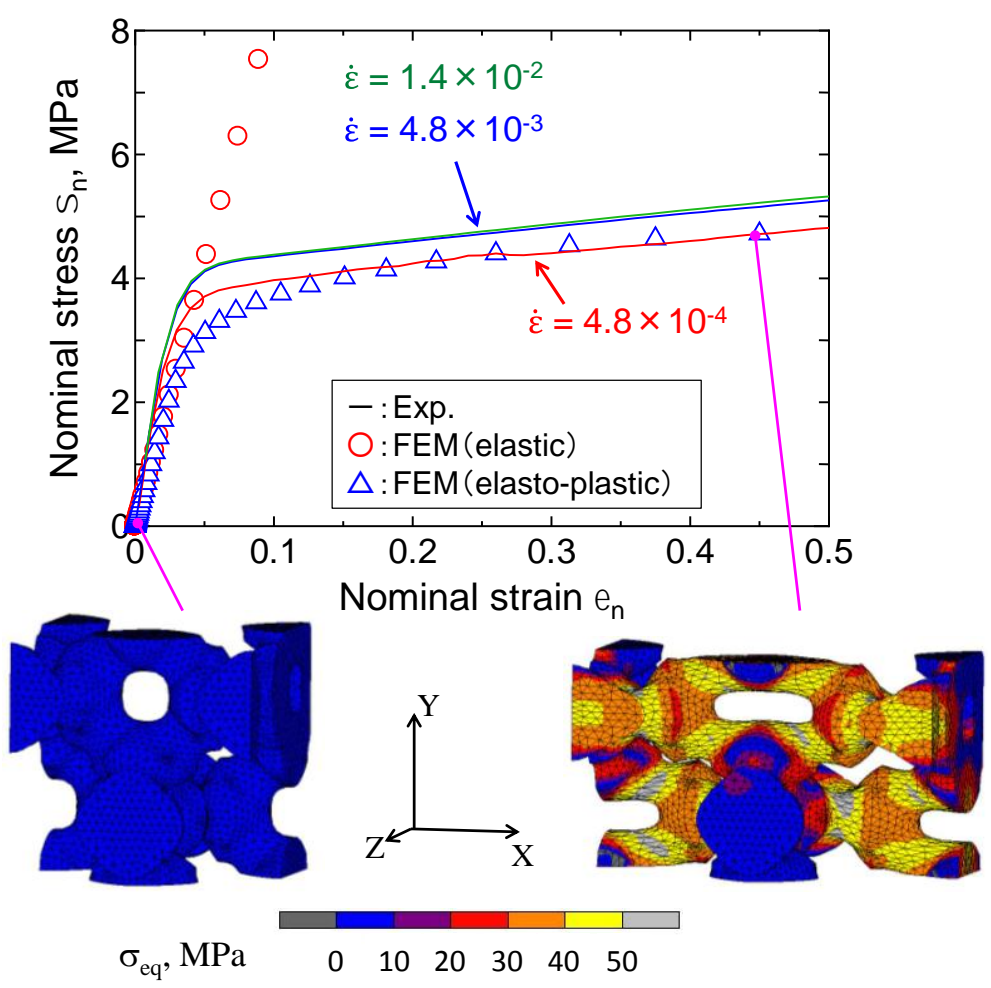

Fig. 11 Nominal stress-strain curves from experiment and FEM(circle: elastic analysis, triangle: elastoplastic analysis). Experimental data were obtained from Figure 3. 
Table 1 Mechanical properties of the PVDF solid matrix.

\begin{tabular}{ccccc}
\hline $\begin{array}{c}\text { Young's } \\
\text { modulus } \\
E, \mathrm{MPa}\end{array}$ & $\begin{array}{c}\text { Poisson's } \\
\text { ratio } v\end{array}$ & $\begin{array}{c}\text { Yield stress } \\
\sigma_{Y}, \mathrm{MPa}\end{array}$ & $\begin{array}{c}\text { Work hardening } \\
\text { strength } K, \mathrm{MPa}\end{array}$ & $\begin{array}{c}\text { Work hardening } \\
\text { exponent } n\end{array}$ \\
\hline 928 & 0.4 & 26.0 & 30.0 & 0.6 \\
\hline
\end{tabular}

Table 2 Mechanical properties (Young's modulus and yield stress) obtainedfrom the experimental stress-strain and FEM computational curves (see Fig.11).

Young's modulus $E, \mathrm{MPa} \quad$ Yield stress $\sigma_{\mathrm{Y}}, \mathrm{MPa}$

Exp. $\left(\dot{\varepsilon}=4.8 \times 10^{-3}\right) \quad 124$

Exp. $\left(\dot{\varepsilon}=4.8 \times 10^{-4}\right) \quad 113 \quad 3.7$

